\title{
Comparison of Antioxidant and Anti-collagenase Activity of Genistein and Epicatechin
}

\author{
Geeta $^{1}$, Wahyu Setia Widodo ${ }^{2}$, Wahyu Widowati ${ }^{3}$, Chrismis Novalinda Ginting ${ }^{4}$, I Nyoman \\ Ehrich Lister ${ }^{4}$, Adek Armansyah ${ }^{4}$, Ermi Girsang ${ }^{1 *}$
}

${ }^{1}$ Master in Biomedical Science Program, Faculty of Medicine, Universitas Prima Indonesia, Medan, Indonesia

${ }^{2}$ Biomolecular and Biomedicine Research Center, Aretha Media Utama, Bandung, Indonesia

${ }^{3}$ Faculty of Medicine, Maranatha Christian University, Bandung, Indonesia

${ }^{4}$ Faculty of Medicine, Universitas Prima Indonesia, Medan, Indonesia

\begin{abstract}
Background: Skin aging is a complex natural process caused by both intrinsic or genetically programmed aging and extrinsic aging caused by environmental factors, such as free radical. The use of antioxidant and anti-collagenase to prevent the aging proses has been known. Natural compounds from plants are one of the sources of antioxidant and anti-collagenase that has ability to prevent aging. Genistein and Epicatechin are the major phenolic compound found in G. max. Objectives: This research was to evaluate the antiaging potential of genistein and epicatechin through antioxidant activity assay (ABTS-reducing activity assay) and collagenase inhibitory activity assay. Methods: Antioxidant analysis of Genistein and Epicatechin was performed by 2,2'- azinobis-3-ethylbenzo-thiazoline-6-sulfonic acid (ABTS) reducing activity Assay. Antiaging assay was conducted through inhibitory of collagenase, one of important enzyme in aging process. Results: ABTS- reducing activity assay showed that both compounds had great ABTS-reducing activity in which epicatechin had better activity than genistein. Epicatechin had low value of $\mathrm{IC}_{50}$ ABTS-reducing activity around $14.39 \mu \mathrm{g} / \mathrm{ml}$ better than genistein with $\mathrm{IC}_{50}$ about $43.17 \mu \mathrm{g} / \mathrm{ml}$. In terms of collagenase inhibitory activity assay, epicatechin had lower value of $\mathrm{IC}_{50}(9.08+-3.46 \mathrm{ug} / \mathrm{ml})$, better than genistein $(98.74+-4.25 \mathrm{ug} / \mathrm{ml})$. Conclusion: Epicatechin had higher antioxidant and anti- collagenase activity compared to Genistein.
\end{abstract}

Keywords: ABTS-reducing activity; anti-collagenase; genistein; epicatechin

*Corresponding author

Email : ermigirsang@unprimdn.ac.id

\section{INTRODUCTION}

Skin aging is natural process caused by intrinsic and extrinsic factor. Intrinsic factor is generally caused by genetically programmed aging that occur over time, whereas extrinsic factor caused by environmental factor such as pollution, harsh weather, ultraviolet damage, and cigarette smoke (Kirkwood, 2005). Sun exposure is the majoring extrinsic factor and responsible to age-related change, such as roughness, fine wrinkles, mottled hyper pigmentation, and loss of skin tone (McCullogh, 2006). Sun exposure can cause photoaging through chronic UV radiation inducing the formation of lipid peroxidase and oxidant (Mukherjee et al., 2011).

Oxidant is produced by endogenous and exogenous source and responsible in aging process. Endogenous oxidant is produced by oxidase catalyzed reaction, mitochondria-catalyzed electron transport reactions, metal-catalyzed reactions, arginine metabolism, and also produced by neutrophils and macrophages during inflammatory condition. Exogenous source oxidant is caused by the exposure of the body to air pollution such as radical NO and consuming food containing metals $(\mathrm{Fe}, \mathrm{Cu})$ and some phenolic compound (Birben et al., 2012).

The use of antioxidant to prevent and treat aging has been known. The antioxidants, such as polyphenols, vitamins, and flavonoid have ability to reduce collagen degradation through reducing FR concentration in the tissues (Ganceviciene et al., 2012). Topical application of antioxidant such as vitamin C, B3, and E can penetrate to the skin and has ability to protect the skin from oxidative damage. Vitamins E ( $\alpha$-tocopherol) can induce the stratum corneum to accelerate the epithelialization, contribute to photoprotection of the skin, and maintains stratum corneum humidity (Ganceviciene et al., 2012; Haftek et al., 2008).

Moreover, proteolytic enzyme also responsible for aging process. Previous study found that the antioxidant could induce the production proteolytic enzyme such as tyrosinase, collagenase, hyaluronidase and elastase (Widowati et al., 2017). Other finding also showed that UV irradiation induce collagenase expression (Rittié \& 
Fisher, 2002). Collagenase is one of protease enzyme that is responsible for degradation of collagen. In terms of skin aging, the use of compound inhibiting activity of collagenase may be useful to prevent loss of skin elasticity and thus good for preventing the aging process (Thring et al., 2009).

Natural compounds from plant extract have been known to have antioxidant and antiaging activity (Rusmana et al., 2017; Widowati et al., 2014; Widowati et al., 2016). One of the plant materials with good antioxidant activity is Soybean Seeds (Lee, 2005). Soybean (Glycine max L.) seed was one of the major sources of proteins, and oils for human and animal food (Yin \& Blachier, 2011). Soybean seed also contains phenolic compound which has great potential for dietary food (Prvulović et al., 2017). Phenolic compounds are secondary metabolite from plant, identified by at least one aromatic ring with one hydroxyl group attached (Lattanzio et al., 2006). Phenolic compounds are diverse from simple structures such as phenolic acid through complex structure such as polyphenol, e.g. flavonoid. Phenolic compound was known to have high antioxidant activity (Cheynier, 2012).

Genistein and epicatechin are the major phenolic compounds found in soybean seed extract (Bhagwat, et al., 2014). Genistein was isoflavonoid compound found in soy and has high potential for prophylaxis and useful to treat various chronic disease and cancer (Ganai \& Farooqi, 2015). Epicatechin was isoflavonoid found in various fruits and vegetables. It has several biological activities such blood pressure-lowering capacity, antioxidant activity, and provides beneficial for cardiovascular and neuropsychological health (Bernatova, 2018).

Although both genistein and epicatechin have numerous biological activities, the antiaging potential of genistein and epicatechin was not studied yet. The aim of this research was to evaluate the antiaging potential of Genistein and Epicatechin through antioxidant activity assay (ABTS- reducing activity assay) and collagenase inhibitory activity assay.

\section{METHODS}

\section{Materials}

The Epicatechin and Genistein that used in this study were purchased from Chengdu Biopurify Phytochemical (Chengdu, BP0634 and BP0538).

\section{ABTS-reducing Activity Assay}

$14 \mathrm{mM}$ ABTS was reacted with $4.9 \mathrm{mM}$ potassium persulfate for 12-16 hour in room temperature and dark condition for preparing the ABTS solution, the mixture was mixed with phosphate-buffered saline (PBS) until the absorbance of solution was $0.70 \pm 0.02$ at 745 nm wavelength. Briefly, $2 \mu \mathrm{L}$ of sample with serial concentrations $(50,25,12.5,6.25,3.13$ and $1.56 \mu \mathrm{g} / \mathrm{ml})$ were added to each well at 96-well microplate, then 198 $\mu \mathrm{L}$ fresh ABTS solution was added and incubated for $6 \mathrm{~min}$ at $30{ }^{\circ} \mathrm{C}$. The absorbance was then measured at $745 \mathrm{~nm}$ wavelength (Widowati et al., 2018, 2016, 2015, 2014). The percent of scavenging activity was calculated with the equation below:

$\%$ scavenging activity $=\frac{\text { control absorbance-sample absorbance }}{\text { control absorbance }} \times 100 \%$

The median inhibitory concentration $\left(\mathrm{IC}_{50}\right)$ of ABTS reducing activity were also calculated.

\section{Collagenase inhibitory activity assay}

Collagenase inhibitory activity assay was conducted based on the method that was elaborated by Wittenauer et al. (2015) with some modification (Utami et al., 2018; Widowati et al., 2018, 2016; Wittenauer, 2015). The mixture solution consisting of $30 \mu \mathrm{L}$ samples with serial concentration $(250,125,62.5,31.25,15.3$, and $7.81 \mu \mathrm{g} /$ $\mathrm{mL}), 10 \mu \mathrm{L}$ collagenase from clostridium histolyticum enzyme $((0.1 \mathrm{mg} / \mathrm{mL}$, sigma C8051), and $60 \mu \mathrm{L}$ buffer tricine $(50 \mathrm{mM}$ tricine, $10 \mathrm{mM}$ calcium chloride, 400 $\mathrm{mM}$ Sodium chloride, $\mathrm{pH} 7.5$ ) were incubated at $37^{\circ} \mathrm{C}$ for $20 \mathrm{~min}$. The control and blank mixture solution also prepared. The control solution consists of $10 \mu \mathrm{L}$ enzyme dan $90 \mu \mathrm{L}$ phosphate buffer and blank solution consists of $10 \mu \mathrm{L}$ enzyme, $80 \mu \mathrm{L}$ phosphate buffer and $30 \mu \mathrm{L}$ samples.

Then, $20 \mu \mathrm{L}$ FALGPA substrate (1 mM, Sigma F5135) was added to the mixture solution except the blank mixture solution. The absorbance of the solution was then measured with microplate reader at $335 \mathrm{~nm}$ wavelength. The percent of collagenase inhibition was calculated with the equation below:

control absorbance-sample absorbance

$\%$ Collagenase inhibition control absorbance

The median inhibitory concentration $\left(\mathrm{IC}_{50}\right)$ of collagenase inhibition activity was also calculated

\section{Data Analysis}

The results were analyzed using the SPSS program with One-Way ANOVA test and followed by Post hoc Tukey HSD test. The test results of $\mathrm{H}_{2} \mathrm{O}_{2}$ scavenging activity and anti-hyaluronidase activity were continued by analysis by determining the Inhibition Concentration 50 $\left(\mathrm{IC}_{50}\right)$ value. 

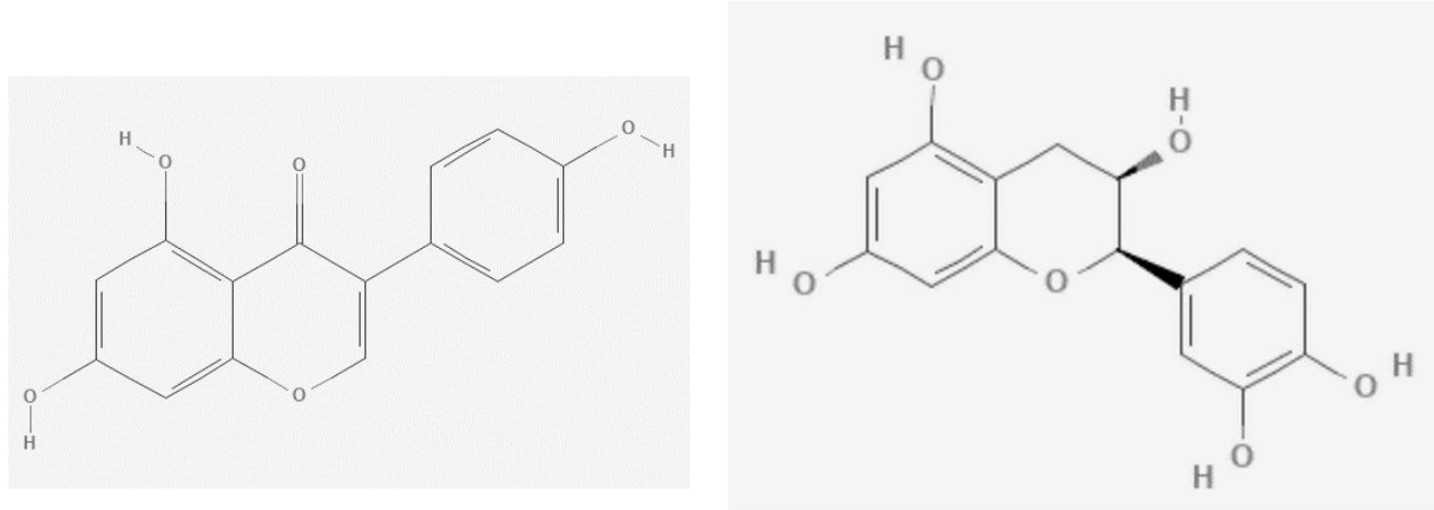

Figure 1. Chemical structure of a) Genistein and b) Epicatechin (Kaiser, 2005)

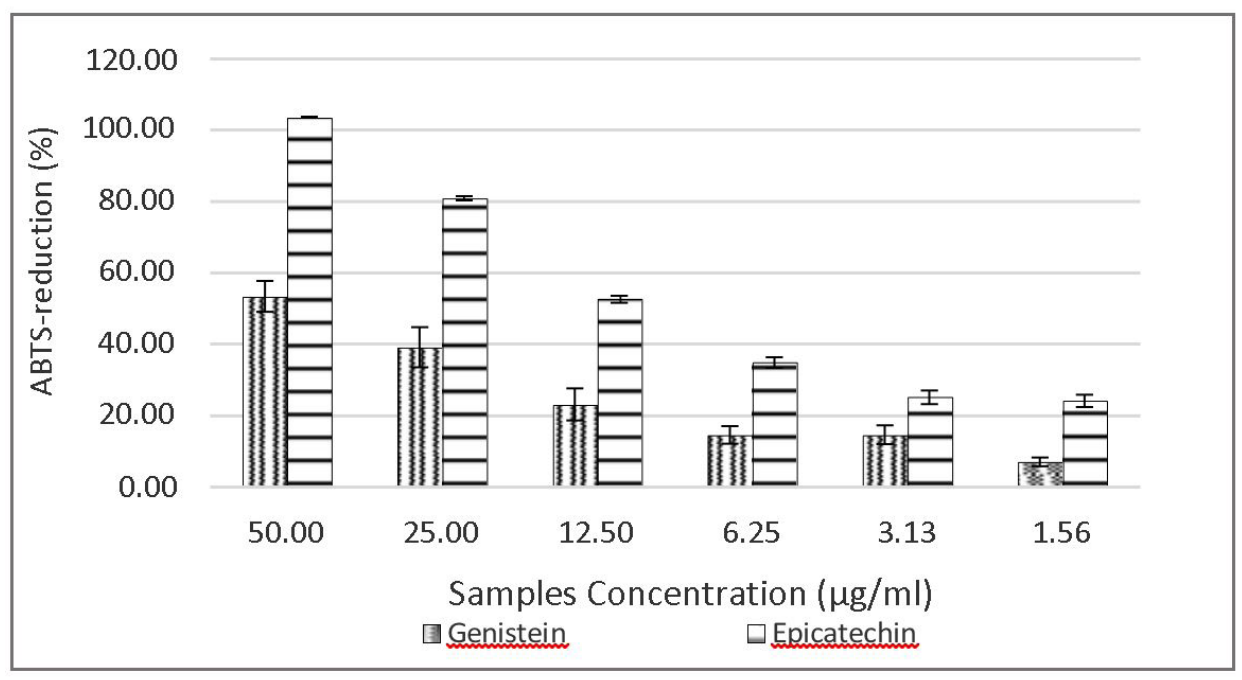

Figure 2. ABTS reduction activity of Epicatechin and Genistein.

\section{RESULTS AND DISCUSSION}

\section{ABTS-reducing Activity}

ABTS-reducing activity assay showed that epicatechin had better ABTS-reducing activity than Genistein. The results of ABTS-scavenging activity showed in Figure 2. The ABTS-scavenging activity of Epicatechin and Genistein increases with the increasing of the concentration of sample. Epicatechin had low value of $\mathrm{IC}_{50}, 14.39 \mu \mathrm{g} / \mathrm{ml}$ better than Genistein with $\mathrm{IC}_{50}$ value around $43.17 \mu \mathrm{g} / \mathrm{ml}$ (Table 1). This result indicated that epicatechin had better antioxidant activity than genistein through ABTS-reducing activity assay.

\section{Collagenase Inhibitory Activity}

Collagenase inhibitory activity was carried out with a spectrophotometric method to measure collagenase activity and to detect potential collagenase inhibitor. The collagenase inhibitory activity assay showed that epicatechin showed better inhibitory activity than genistein (Figure 3). Collagenase inhibitory activity of epicatechin and genistein based on $\mathrm{IC}_{50}$ value showed in Table 2. Table 2. Showed that Epicatechin has lower
$\mathrm{IC}_{50}$ value $(79.08 \pm 3.46)$ better than Genistein with $\mathrm{IC}_{50}$ value around $98.74 \pm 4.25$ (Table 2 ).

\section{Discussion}

The use of natural compounds from plant extract has been widely use to prevent and treat numerous diseases. It is because plant extract contains important compounds having biological activity. One of the most important compounds from plant extract are phenolic compounds (Cheynier, 2012). Phenolic compounds are secondary metabolites from plant having large diversity in structure from simple molecules (e.g. caffeic acid, gallic acid, and vanillin) to flavonoid. Phenolic compound has antioxidant activity and can protect the body against ROS (Ozcan et al., 2014; Widowati et al., 2018).

Soybean (Glycine max) seed contains various phenolic compound especially flavonoid such as genistein, epicatechin, daidzein, daidzin, glycitin, genistin, etc (Lee, 2005). Total isoflavone in soybean seed was 558.2 $\mu \mathrm{g} / \mathrm{g}-1716.9 \mu \mathrm{g} / \mathrm{g}$ in range (Sakthivelu et al., 2008). The major flavonoid compound in soybean seed was genistein and epicatechin (Bhagwat, 2014). Genistein 


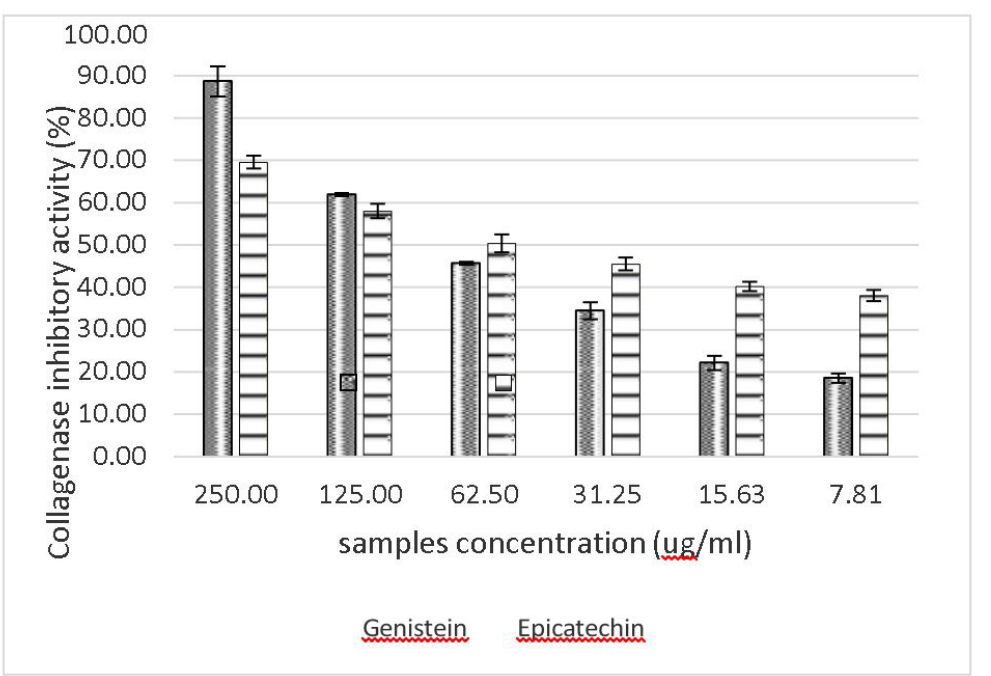

Figure 3. Collagenase inhibitory activity of Genistein and Epicatechin.

and epicatechin have various biological activity to treat some degenerative disease and cancer (Bernatova, 2018; Ganai \& Farooqi, 2015).

Aging process is natural process over time, but free radicals also can accelerate the aging process. Aging process can be identified by both physical and physiological change. Physical change can be characterized by wrinkle, lessen skin elasticity, uneven pigmentation, brown spot, laxity and leathery appearance (Yaar \& Gilchrest, 2007). There are two different type of aging, first is chronological aging which is caused by genetically programmed aging over time and second is photoaging or premature aging causes by environmental factor (Mukherjee et al., 2011). Photoaging is caused by exposure of the skin to UVradiation. UV radiation from the sun activate the MMPs enzyme, a collagenase enzyme group causing dermal tissue breakdown. UV radiation is also responsible for the generation of Reactive Oxygen Species (ROS) such as hydrogen peroxide and inhibits procollagen collagen (Fisher et al., 2002). The generation of ROS can cause oxidative damage and also tissue damage in the skin and make the loss of elasticity in the skin (McDaniel et al., 2018). The production of MMPs or collagenase cause the breakdown the skin tissue and also caused the loss of skin elasticity (Lademann et al., 2011).

Natural compound has been known to protect the skin from the UV radiation. Tocopherol, ascorbic acid and polyphenol, natural remedies from plant extract have been reported has ability to protect skin from UVradiation (Masaki, 2010). Natural compound also has antioxidant and antiprotease activity that has good benefit to prevent skin aging. Some compounds such as xanthones (Utami et al., 2017), gallic acid, $\beta$-carotten, catechin (Mukherjee et al., 2011), Eugenol, Hesperidin (Widowati et al., 2018), myricetin (Mukherjee et al., 2011), rutin, quecertin (Rusmana et al., 2017), Coumaric acid, vanillin (Widowati et al., 2016) have antioxidant and antiprotease (anti-collagenase, anti-hyaluronidase, anti-elastase, and anti-tyrosinase). Crude extract from plant also has antioxidant and antiprotease activity such as tea extract (Thring et al., 2009; Widowati et al., 2015), rose flowers extract (Thring et al., 2009), cocoa pod extract (Abdul Karim et al., 2014), Hypericum hircinum $L$ extract (Mandrone et al., 2015), etc.

In this research, epicatechin showed better antioxidant activity through ABTS-reducing assay where epicatechin has lower $\mathrm{IC}_{50}$ value of ABTS-reducing activity than genistein, which is relevant to previous study where epicatechin has better scavenging activity than genistein through DPPH free radical scavenging assay (Lee, 2005). In this essay, the generation of ABTS (2,29-azinobis-(3ethylbenzothiazoline-6-sulfonic acid) pre-formed radical mono-cation was performed by oxidation of ABTS with potassium persulfate and will be reduced in the present of hydrogen-donating antioxidant. The antioxidant activity of the phenol compound was determined by the amount of hydroxyl group. The hydroxyl group in the phenolic compound will donate the hydrogen ion to the chain carrying ROD* radicals (Foti, 2007). The better antioxidant activity of Epicatechin than Genistein was predicted due to the higher amount of hydroxyl group in Epicatechin than Genistein as seen in Figure 1. Other finding also said that several factor responsible for increasing radical scavenging activity such as hydroxy group in atom $\mathrm{C}$ number 3 and 5 in $\mathrm{A}$ ring, orthodihydroxy structure in the $\mathrm{B}$ ring, and 2,3-double bond in the C-ring in conjugation with a 4-oxo function (Dugas et al., 2000; Widowati et al., 2017).

The collagenase inhibitory assay showed that epicatechin has lower value of $\mathrm{IC}_{50}$ than Genistein. The $\mathrm{IC}_{50}$ of Epicatechin was $79.08 \pm 3.46$ better than Genistein $(98.74 \pm 4.25)$. If we compared with other research, 
$\mathrm{IC}_{50}$ of Epicathecin and Genistein is better than another subtance such as Hisperidine (IC50: 198.09 $\pm 14.01 \mu \mathrm{g} /$ $\mathrm{ml}$ ) and Eugenol (IC50: 225.10 $\pm 31.25 \mu \mathrm{g} / \mathrm{ml}$ ) (Widowati et al., 2018).

Collagenase is enzyme that is responsible for degradation of collagen matix. There are three types of collagenase in human, MMP (Matrixmetallo protease)1, MMP-8 and MMP-13 (Ricciarelli et al., 1999). UVradiation increases the level of the MMPs in the skin and accelerates photoaging process (Fisher et al., 2002). This study indicates that epicathecin and genistein have poteintial as antiaging tretment though antioxidant and anticollagenase activity.

\section{CONCLUSION}

In summary, natural compounds from soybean (Glycine max) seed extract (genistein and epicathecin) have antioxidant and anticollagenase activity. Epicatechin has better antioxidant and antiaging activity than genistein through ABTS-reducing activity assay and collagenase activity.

\section{ACKNOWLEDGMENT}

This research was supported by University of Prima Indonesia and Biomolecular \& Biomedical Research Center, Aretha Medika Utama, Bandung, Indonesia for laboratory facilities and research methodology. We are thankful to Ubaydillah Z. M and Annisa Amalia, Rizal Rizal for their valuable assistance.

\section{REFERENCES}

Karim, A., Azlan, A., Ismail, A., Hashim, P., Abd Gani, S. S., Zainudin, B. H., \& Abdullah, N. A. (2014). Phenolic composition, antioxidant, anti-wrinkles and tyrosinase inhibitory activities of cocoa pod extract. BMC Complementary and Alternative Medicine, 14(1), 381. https://doi.org/10.1186/1472-6882-14-381

Bernatova, I. (2018). Biological activities of $(-)$-epicatechin and (-)-epicatechin-containing foods: Focus on cardiovascular and neuropsychological health. Biotechnology Advances, 36(3), 666- 681. https://doi. org/10.1016/j.biotechadv.2018.01.009

Bhagwat, Seema, David B. Haytowitz, and J. M. H. (2014). USDA database for the flavonoid content of selected foods, Release 3.1. Beltsville, MD, USA.

Birben, E., Sahiner, U. M., Sackesen, C., Erzurum, S., \& Kalayci, O. (2012). Oxidative Stress and Antioxidant Defense. World Allergy Organization Journal, 5(1), 9-19. https://doi.org/10.1097/WOX.0b013e3182439613
Cheynier, V. (2012). Phenolic compounds: from plants to foods. Phytochemistry Reviews, 11(2-3), 153-177. https://doi.org/10.1007/s11101-012-9242-8

Dugas, A. J., Castañeda-Acosta, J., Bonin, G. C., Price, K. L., Fischer, N. H., \& Winston, G. W. (2000). Evaluation of the Total Peroxyl Radical-Scavenging Capacity of Flavonoids: Structure-Activity Relationships. Journal of Natural Products, 63(3), 327-331. https://doi. org/10.1021/np990352n

Fisher, G. J., Kang, S., Varani, J., Bata-Csorgo, Z., Wan, Y., Datta, S., \& Voorhees, J. J. (2002). Mechanisms of Photoaging and Chronological Skin Aging. Archives of Dermatology, 138(11). https://doi.org/10.1001/ archderm.138.11.1462

Foti, M. C. (2007). Antioxidant properties of phenols. Journal of Pharmacy and Pharmacology, 59(12), 16731685. https://doi.org/10.1211/jpp.59.12.0010

Ganai, A. A., \& Farooqi, H. (2015). Bioactivity of genistein: A review of in vitro and in vivo studies. Biomedicine \& Pharmacotherapy, 76, 30-38. https://doi. org/10.1016/j.biopha.2015.10.026

Ganceviciene, R., Liakou, A. I., Theodoridis, A., Makrantonaki, E., \& Zouboulis, C. C. (2012). Skin antiaging strategies. Dermato - Endocrinology, 4(3), 308319. https://doi.org/10.4161/derm.22804

Haftek, M., Mac-Mary, S., Bitoux, M.-A. Le, Creidi, P., Seité, S., Rougier, A., \& Humbert, P. (2008). Clinical, biometric and structural evaluation of the long-term effects of a topical treatment with ascorbic acid and madecassoside in photoaged human skin. Experimental Dermatology, 17(11), 946-952. https://doi.org/10.1111/ j.1600-0625.2008.00732.x

Kaiser J. (2005). Science resources. Chemists want NIH to curtail database. Science, 308(5723), 774. https://doi. org/10.1126/science.308.5723.774a

Kirkwood, T. B. L. (2005). Understanding the Odd Science of Aging. Cell, 120(4), 437-447. https://doi. org/10.1016/j.cell.2005.01.027

Lademann, J., Meinke, M. C., Sterry, W., \& Darvin, M. E. (2011). Carotenoids in human skin. Experimental Dermatology, 20(5), 377-382. https://doi.org/10.1111/ j.1600-0625.2010.01189.x

Lattanzio, V., Lattanzio, V. M. T., \& Cardinali, A. (2006). Role of phenolics in the resistance mechanisms of plants against fungal pathogens and insects. Phytochemistry: Advances in Research (Vol. 661). https://doi.org/10.1080 


\section{$/ 19439342.2018 .1452778$}

Lee, C. (2005). Relative antioxidant activity of soybean isoflavones and their glycosides. Food Chemistry, 90(4), 735-741. https://doi.org/10.1016/j. foodchem.2004.04.034

Mandrone, M., Lorenzi, B., Venditti, A., Guarcini, L., Bianco, A., Sanna, C., ... Antognoni, F. (2015). Antioxidant and anti-collagenase activity of Hypericum hircinum L. Industrial Crops and Products, 76, 402-408. https://doi.org/10.1016/j.indcrop.2015.07.012

McCullogh, J. L. (2006). Prevention and Treatment of Skin Aging. Annals of the New York Academy of Sciences, 1067(1), 323-331. https://doi.org/10.1196/ annals.1354.044

McDaniel, D., Farris, P., \& Valacchi, G. (2018). Atmospheric skin aging-Contributors and inhibitors. Journal of Cosmetic Dermatology, 17(2), 124-137. https://doi.org/10.1111/jocd.12518

Mukherjee, P. K., Maity, N., Nema, N. K., \& Sarkar, B. K. (2011). Bioactive compounds from natural resources against skin aging. Phytomedicine, 19(1),6473. https://doi.org/10.1016/j.phymed.2011.10.003

Ozcan, T., Akpinar-Bayizit, A., Yilmaz-Ersan, L., \& Delikanli, B. (2014). Phenolics in Human Health. International Journal of Chemical Engineering and Applications, 5(5), 393-396. https://doi.org/10.7763/ IJCEA.2014.V5.416

Prvulović, D., Malenčić, Đ., \& Miladinović, J. (2017). Antioxidant Activity and Phenolic Content of Soybean Seeds Extracts. Агрознање, 17(2), 121. https://doi. org/10.7251/AGREN1602121P

Ricciarelli, R., Maroni, P., Ozer, N., Zingg, J. M., \& Azzi, A. (1999). Age-dependent increase of collagenase expression can be reduced by alpha-tocopherol via protein kinase C inhibition. Free Radical Biology \& Medicine, 27(7-8), 729-737. Retrieved from http:// www.ncbi.nlm.nih.gov/pubmed/10515576

Rittié, L., \& Fisher, G. J. (2002). UV-light-induced signal cascades and skin aging. Ageing Research Reviews, 1(4), 705-720. Retrieved from http://www.ncbi.nlm.nih.gov/ pubmed/12208239

Rusmana, D., Wahyudianingsih, R., Elisabeth, M., Balqis, B., Maesaroh, M., \& Widowati, W. (2017). Antioxidant Activity of Phyllanthus niruri Extract, Rutin and Quercetin. The Indonesian Biomedical Journal,
9(2), 84. https://doi.org/10.18585/inabj.v9i2.281

Sakthivelu, G., Akitha Devi, M. K., Giridhar, P., Rajasekaran, T., Ravishankar, G. A., Nikolova, M. T., ... Kosturkova, G. P. (2008). Isoflavone Composition, Phenol Content, and Antioxidant Activity of Soybean Seeds from India and Bulgaria. Journal of Agricultural and Food Chemistry, 56(6), 2090-2095. https://doi. org/10.1021/jf072939a

Thring, T. S., Hili, P., \& Naughton, D. P. (2009). Anticollagenase, anti-elastase and anti-oxidant activities of extracts from 21 plants. BMC Complementary and Alternative Medicine, 9(1), 27. https://doi. org/10.1186/1472-6882-9-27

Utami, S., Adityaningsari, P., Sosiawan, I., Endrini, S., Sachrowardi, Q. R., Laksono, S. P., ... Widowati, W. (2017). Antioxidants and Anticholinesterase Activities of the Characterized Ethanolic of Ripe Sesoot (Garcinia picrorrhiza Miq.) Fruit Extract (GpKar) and Xanthone. Majalah Obat Tradisional, 22(3), 160. https://doi. org/10.22146/mot.31548

Utami, S., Sachrowardi, Q. R., Damayanti, N. A., Wardhana, A., Syarif, I., Nafik, S., ... Widowati, W. (2018). Antioxidants, anticollagenase and antielastase potentials of ethanolic extract of ripe sesoot (Garcinia picrorrhiza Miq.) fruit as antiaging. Journal of Herbmed Pharmacology, 7(2), 88-93. https://doi.org/10.15171/ jhp.2018.15

Widowati W., Noverina R., Ayuningtyas W., Kurniawa D., Faried A., Laksmitawati D., Rihibiha D., Rizal R., Suciati T., S. S. (2018). Reactive Oxygen Species and Aging Mechanism. Reactive Oxygen Species (ROS) Mechanism and Role in Health and Disease. In Shannon Wilkerson (Ed.), Reactive Oxygen Species (ROS): Mechanism and Role in Helath and Disease (pp. 101134). New York: Nova Science Publisher

Widowati, W., B, W. J., Nadya, S., Amalia, A., Arumwardana, S., Kusuma, H. S. W., \& Arinta, Y. (2018). Antioxidant and Antiaging Activities of Jasminum Sambac Extract, and its Compounds. Journal of Reports in Pharmaceutical Sciences, 7(3), 270-285

Widowati, W., Darsono, L., Suherman, J., Yelliantty, Y., \& Maesaroh, M. (2014). High Performance Liquid Chromatography (HPLC) Analysis, Antioxidant, Antiaggregation of Mangosteen Peel Extract (Garcinia mangostana L.). International Journal of Bioscience, Biochemistry and Bioinformatics, 4(6), 458-466. https:// doi.org/10.17706/ijbbb.2014.4.6.458-466 
Widowati, W., Fauziah, N., Herdiman, H., Afni, M., Afifah, E., Kusuma, H. S. W., ... Rihibiha, D. D. (2016). Antioxidant and Anti Aging Assays of Oryza sativa Extracts, Vanillin and Coumaric Acid. Journal of Natural Remedies, 16(3), 88. https://doi.org/10.18311/ jnr/2016/7220

Widowati, W., Herlina, T., Ratnawati, H., Constantia, G., Deva, I. D. G. S., \& Maesaroh, M. (2015). Antioxidant Potential of Black, Green and Oolong Tea Methanol Extracts. Biology, Medicine, \& Natural Product Chemistry, 4(2), 35. https://doi.org/10.14421/ biomedich.2015.42.35-39

Widowati, W., Rani, A. P., Hamzah, R. A., Arumwardana, S., Afifah, E., Kusuma, H. S. W., ... Amalia, A. (2017). Antioxidant and Antiaging Assays of Hibiscus sabdariffa Extract and Its Compounds. Natural Product Sciences, 23(3), 192. https://doi.org/10.20307/nps.2017.23.3.192
Wittenauer, J., Mäckle, S., Sußmann, D., SchweiggertWeisz, U., \& Carle, R. (2015). Inhibitory effects of polyphenols from grape pomace extract on collagenase and elastase activity. Fitoterapia, 101, 179-187. https:// doi.org/10.1016/j.fitote.2015.01.005

Yaar, M., \& Gilchrest, B. A. (2007). Photoageing: mechanism, prevention and therapy. British Journal of Dermatology, 157(5), 874-887. https://doi.org/10.1111/ j.1365-2133.2007.08108.x

Yin, Y., A., A., \& Blachier, F. (2011). Soya Bean Meal and Its Extensive Use in Livestock Feeding and Nutrition. Soybean and Nutrition. InTech. https://doi. org/10.5772/18823 